\title{
Protection Studies of Electrical Power Systems with Distributed Genera- tion Using an Open Library of Protective Relays
}

\section{Felipe B. B. Rolim (IC), Fernanda C. T. Arioli (PQ): \\ Abstract}

The increase in the penetration level of distributed generation in electrical power distribution systems all around the world resulted in the need for specialized and easy tools to help engineers, researchers and students in understanding and solving technical challenges related to this reality. Among the studies that can be benefited by these simulation tools, one can highlight studies related to power system protection. Consequently, detailed and reliable models are needed. In this context, the research group of the School of Electrical and Computer Engineering from University of Campinas developed a relay library (with dynamic models): DG ProtectionLib. The objective is to offer this library online and free, so its use can be widespread and the models can be improved and used to support protection studies. This work aims to conduct protection studies in distribution systems with different technologies of distributed generators and provide representative examples of application of these relays. The development of a didactic presentation of the library models will assist further studies in this area and the use of the library by other researchers, students and engineers. Keywords: Distributed Generator, Electromagnetic Transients Simulation, Protection Relay.

\section{Introduction}

Several technologies are used as distributed generation (DG), for example, synchronous generators (biomass or small hydro); induction generators (mainly used in wind generation) and photovoltaic solar generators. Each technology of DG presents different contribution characteristics for short-circuit, requiring studies that take into account such features. In this context, the electromagnetic transient simulation programs (EMTP) are powerful tools for dynamic analysis in distribution systems. Although many models are available in EMTP, relays models are not present. Therefore, this work aims to conduct protection studies in distribution systems with DGs and provide representative examples of application of relays from an open library developed by the research group from University of Campinas ${ }^{1,2}$. The development of a didactic presentation of the library models will assist further studies in this area and the use of the library by other researchers, students and engineers. The models of this library are presented in Figure 1.
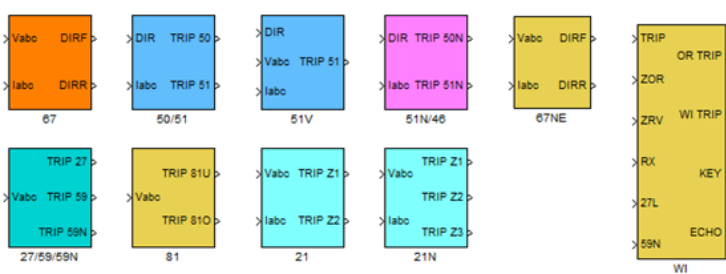

Figure 1. DG ProtectionLib library ${ }^{1,2}$ and a fault is applied at instant $t=0.1 \mathrm{~s}$. One can observe that the relay succeessfully trips at $\mathrm{t}=0.6$ $\mathrm{s}$ (bottom curve).
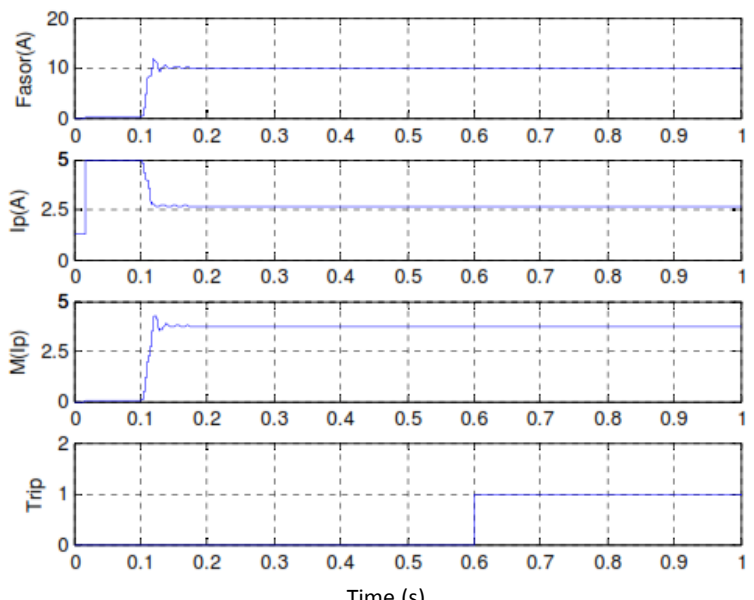

Figure 2. Trip of relay $51 \mathrm{~V}$.

\section{Conclusions}

This work presents case studies exploring a didactic open library of protective relays that was developed by the research group from Unicamp. The available models can assist other researchers, students and engineers that objective to study the protection of distributed generators.

\section{Acknowledgement}

This work was supported by FAPESP. Process No. 2014/ 24914-4.

\footnotetext{
Salles, N. J. de, "Modelagem e Análise Dinâmica de Sistemas de Proteção de Redes de Distribuição de Energia Elétrica na Presença de Geradores Síncronos". Dissertação de mestrado. FEEC/Unicamp, 2007.

2 Salles, N. J. de, "Modelagem Multiambiente de Sistemas de Proteção para Ilhamento Intencional de Geradores Síncronos Distribuídos". Tese de doutorado. FEEC/Unicamp, 2013
} 